\title{
Guiding concepts for park and wilderness stewardship in an era of global environmental change
}

Richard J Hobbs ${ }^{1 *}$, David N Cole ${ }^{2}$, Laurie Yung ${ }^{3}$, Erika S Zavaleta ${ }^{4}$, Gregory H Aplet ${ }^{5}$, F Stuart Chapin III ${ }^{6}$, Peter B Landres ${ }^{2}$, David J Parsons ${ }^{2}$, Nathan L Stephenson ${ }^{7}$, Peter S White ${ }^{8}$, David M Graber ${ }^{9}$, Eric S Higgs ${ }^{10}$, Constance I Millar ${ }^{11}$, John M Randall ${ }^{12}$, Kathy A Tonnessen ${ }^{13}$, and Stephen Woodley ${ }^{14}$

The major challenge to stewardship of protected areas is to decide where, when, and how to intervene in physical and biological processes, to conserve what we value in these places. To make such decisions, planners and managers must articulate more clearly the purposes of parks, what is valued, and what needs to be sustained. A key aim for conservation today is the maintenance and restoration of biodiversity, but a broader range of values are also likely to be considered important, including ecological integrity, resilience, historical fidelity (ie the ecosystem appears and functions much as it did in the past), and autonomy of nature. Until recently, the concept of "naturalness" was the guiding principle when making conservation-related decisions in park and wilderness ecosystems. However, this concept is multifaceted and often means different things to different people, including notions of historical fidelity and autonomy from human influence. Achieving the goal of nature conservation intended for such areas requires a clear articulation of management objectives, which must be geared to the realities of the rapid environmental changes currently underway. We advocate a pluralistic approach that incorporates a suite of guiding principles, including historical fidelity, autonomy of nature, ecological integrity, and resilience, as well as managing with humility. The relative importance of these guiding principles will vary, depending on management goals and ecological conditions.

Front Ecol Environ 2010; 8(9): 483-490, doi:10.1890/090089 (published online 2 Dec 2009)

$F^{\circ}$ or most large US park and wilderness areas, legislation and management policies call for preservation, unimpaired, in perpetuity. Central to the notions of protection, preservation, and lack of impairment has been added the concept of "naturalness", local ecological and environmental conditions imagined to persist over time, in the absence of human intervention. For much of the 20th century, this idea of naturalness as the guiding concept for stewardship

\section{In a nutshell:}

- Maintaining "naturalness"- which has different meanings to different people - is no longer suitable as a management objective in park and wilderness areas

- Improved understanding of ecosystem dynamics and the pervasive threats of global change require increasing focus on the type and extent of management intervention required

- Guiding principles, including historical fidelity, ecological integrity, and resilience, can form the basis of a more focused but pluralistic approach to park and wilderness management

\footnotetext{
${ }^{1}$ School of Plant Biology, University of Western Australia, Crawley, Western Australia, Australia *(rhobbs@cyllene.uwa.edu.au); ${ }^{2}$ Aldo Leopold Wilderness Research Institute, USDA Forest Service, Rocky Mountain Research Station, Missoula, MT; ${ }^{3}$ Wilderness Institute, College of Forestry and Conservation, University of Montana, Missoula, MT; (continued on p490)
}

of park and wilderness areas remained largely unchallenged. Many scientists, managers, and conservationists assumed that natural conditions could be preserved through non-intervention and that this would ensure longterm conservation of biodiversity and ecosystems within protected-area boundaries.

Recently, emphasis has shifted, and the conservation of biological diversity has become an increasingly important goal for many protected areas; this includes the preservation of genetic diversity, species, biotic communities, and the fundamental physical and biological processes that organisms and communities depend on, as well as "natural" rates of change (NPS 2006). In addition, people have increasingly questioned the definition of naturalness and the feasibility of maintaining natural conditions in park and wilderness areas. Growing awareness of extensive Native American influences on "natural" landscapes and an understanding of the dynamism and change inherent in "natural" systems raise questions about what this term really means. With increasing recognition of the potential effects of climate change has come awareness that it may not even be desirable to maintain the historical conditions we often associate with naturalness. Is the concept of naturalness still sufficient to guide park and wilderness stewardship? Should it be reinterpreted or more precisely defined? Are there other concepts that should complement it or take its place?

In this paper, we examine the question of intervention in 
a conservation context and review the reasons why naturalness (as commonly defined) is increasingly problematic as a central goal for park and wilderness-area management. We explore several alternative guiding concepts. Some (eg historical fidelity) are concepts long familiar to protected-area managers. Others (eg ecological integrity) have been deployed at local scales by non-governmental organizations and at large spatial scales by federal agencies, such as Parks Canada, for example. Additional guiding concepts (eg resilience) have been proposed more recently and are still being developed. These alternative concepts are not all mutually exclusive. We include them to suggest a range of possible directions and sources from which to construct a set of pluralistic park and wilderness-area management goals and guidelines, appropriate to today's evolving knowledge about ecological systems, rapid global change, and an increasing emphasis on the importance of reserves for protecting native biodiversity. We focus primarily on the US and the particulars of policy that are relevant there. We also focus on those protected areas for which naturalness has been the management goal (ie US national parks and wilderness areas, and other, similarly managed protected areas). We recognize that many different types of protected areas exist worldwide, from strictly protected wilderness areas to multiple-use biosphere reserves, and that these encompass a broad range of management objectives and approaches. While naturalness is not always an explicit goal for management in other parts of the world, there is often an assumption (implicit or explicit) that naturalness is an important quality to consider (eg Peterken 1996). Our findings are therefore likely to have broader relevance to systems of protected areas in other countries, and may help guide their management in the context of a rapidly changing world.

\section{The dilemma of intervention}

Given that human activities are altering park and wilderness ecosystems, the most important decision park managers face is whether or not (or under what circumstances) to intervene through active management (Landres et al. 1998). Much of what we call intervention and active management involves ecological restoration - "the process of assisting the recovery of ecosystems that have been damaged, degraded, or destroyed" (Society for Ecological Restoration International Science and Policy Working Group 2004). We use the more generic term, intervention, to include any prescribed course of action that intentionally alters ecosystem trajectories, and to avoid the connotation of a return to past conditions. Interventions range from lighting fires to culling ungulate populations, from thinning forests to assisted migration of individuals or species better adapted to changing conditions (Hobbs and Cramer 2008). Some are one-time actions, such as introducing a species and observing whether it can thrive in a new site. Others are ongoing, such as liming water bodies to mitigate the effects of acid deposition. Some interven- tions are small in scale (eg actively maintaining a 10-ha sequoia or Joshua tree forest at a location no longer ideal for the species), while others might be on a large scale (eg burning tens of thousands of hectares of forest annually).

The decision not to intervene is also a deliberate and intentional management decision, with very different outcomes than those from active management. Some of the language in the US Wilderness Act - in which wilderness is defined as a place "where the Earth and its community of life are untrammeled by man" - argues against intervention. To be untrammeled, a place should not be intentionally controlled or manipulated for any purpose, even for the conservation of biodiversity (Cole 2000). National Park Service (NPS) policy is more amenable to intervention, stating that intervention in natural biological or physical processes will be the exception, not the rule, but that it is appropriate "to restore ecosystem functioning that has been disrupted by past or ongoing human activities" (NPS 2006). In the future, park and wilderness-area managers will need to operate across this entire spectrum, from non-intervention to active transformation.

Decisions to intervene in park and wilderness ecosystems should be based on goals (White and Bratton 1980). The desired outcomes of interventions should be specified, in the form of operational objectives and targets that identify which elements and processes should be preserved and in what state these should be maintained (Christensen 1988). NPS Management Policies (NPS 2006) state that decisions to intervene must "be based on clearly articulated, well-supported management objectives". Choices regarding when and how to intervene require a clearer understanding of naturalness.

\section{- Managing for naturalness}

The centrality of naturalness as the guiding principle behind park management is clear in foundational legislation, such as the NPS Organic Act (1916). This Act declared that the fundamental purpose of parks was "to conserve the scenery and the natural and historic objects and the wild life therein... unimpaired for the enjoyment of future generations". The policies developed to serve this mandate, described in then-Secretary of the Interior Franklin Lane's letter to NPS Director Stephen Mather (Sellars 1997), states that "every activity of the Service is subordinate to duties imposed upon it to faithfully preserve the parks for posterity in essentially their natural state". More recent policies direct park managers to preserve "components and processes in their natural condition", defining "natural condition" as "the condition of resources that would occur in the absence of human dominance over the landscape" (NPS 2006). The Wilderness Act (1964) similarly defines wilderness (among other things) as an area "protected and managed so as to preserve its natural conditions".

But what does it mean to preserve natural conditions 
and manage for naturalness? One sense of the word "natural" refers to everything other than the supernatural (Ralston 2001). In the realm of park and wilderness stewardship, the natural world has been contrasted with the human-dominated world. In this sense, two related characteristics of naturalness are a lack of human effects on ecosystems and an absence of intentional human control of ecosystems. Interwoven with this has been the notion that natural ecosystems are stable, selfregulating, and in equilibrium. A fourth commonly perceived characteristic of naturalness has been a high degree of historical fidelity (Higgs 2003); natural ecosystems should appear and function much as they did in the past. This has led park and wilderness-area managers to use past conditions as benchmarks for the future.

These definitions reflect scientific and societal assumptions about ecosystems that persisted for much of the 20th century. The idea that North American ecosystems had been stable for long periods, unaffected by humans prior to European settlement, dominated conservation discourse. Park and wilderness areas were assumed to be large enough to sustain themselves over time, so it seemed possible to preserve the ecosystems and species currently occupying them simply by avoiding commercial exploitation, development, and intervention in biological and physical processes. Maintaining naturalness would, it was felt, simultaneously meet such diverse goals as conserving wildlife, maintaining "vignettes of primitive America" (Leopold et al. 1963) by keeping ecosystems relatively unchanged over time, and respecting nature's autonomy (Heyd 2005; Ridder 2007) by avoiding intervention.

\section{- Naturalness challenged}

The adequacy of naturalness as the guiding concept for park and wilderness stewardship has been challenged as protected-area goals have evolved, scientific knowledge has improved, and the sphere of human influence has become global. In today's context, managing for some aspects of naturalness often violates other aspects of it such as when active intervention (intentional human control) is necessary to prevent transformation by introduced species (pervasive human influence and a departure from historical conditions). However, we now know that natural ecosystems are highly dynamic (Wu and Loucks 1995). Therefore, if we are to allow for the free play of biological and physical processes, including evolutionary change, we cannot expect future park landscapes to look the same as they did in the past (White and Bratton 1980). We have also learned that many so-called natural park and wilderness ecosystems in North America have been extensively affected by indigenous peoples, particularly through burning and hunting (Kay 1995; Pyne 1997; Mann 2005). Past human influence has not been pro-

found everywhere (Vale 2002). However, in many parks and wilderness areas, conserving native biological diversity may require maintaining certain historical human influences, while other parks, such as most of those in Alaska, are mandated to continue providing opportunities for subsistence hunting and fishing by indigenous residents (Chapin 2007).

We have also learned that even the most remote park and wilderness ecosystems have already been, and will continue to be, substantially affected by modern human activities (Cole and Landres 1996). Indeed, recent global analyses indicate that the majority of the world's ecosystems have been modified by human activity to some extent (Sanderson et al. 2002; Alessa and Chapin 2008; Ellis and Ramankutty 2008; Haines et al. 2008). Climate change, altered fire regimes, invasive species, and an array of other influences all act and interact to produce ecosystem change. The magnitude of these influences past and future - has been and will be variable. Nevertheless, in many places, the goal of biodiversity conservation will compel us to actively manage ecosystems to mitigate the inadvertent effects of human activity at regional to global scales, compromising our desire to respect nature's autonomy by avoiding intervention.

In short, the many meanings of the term naturalness increasingly conflict with one another and fall short of capturing the expanding range of park values. This forces managers to choose among protected-area values and among the traditional meanings of naturalness. In particular, park managers in the US confront the dilemma of whether and how to intervene in "natural" processes and 

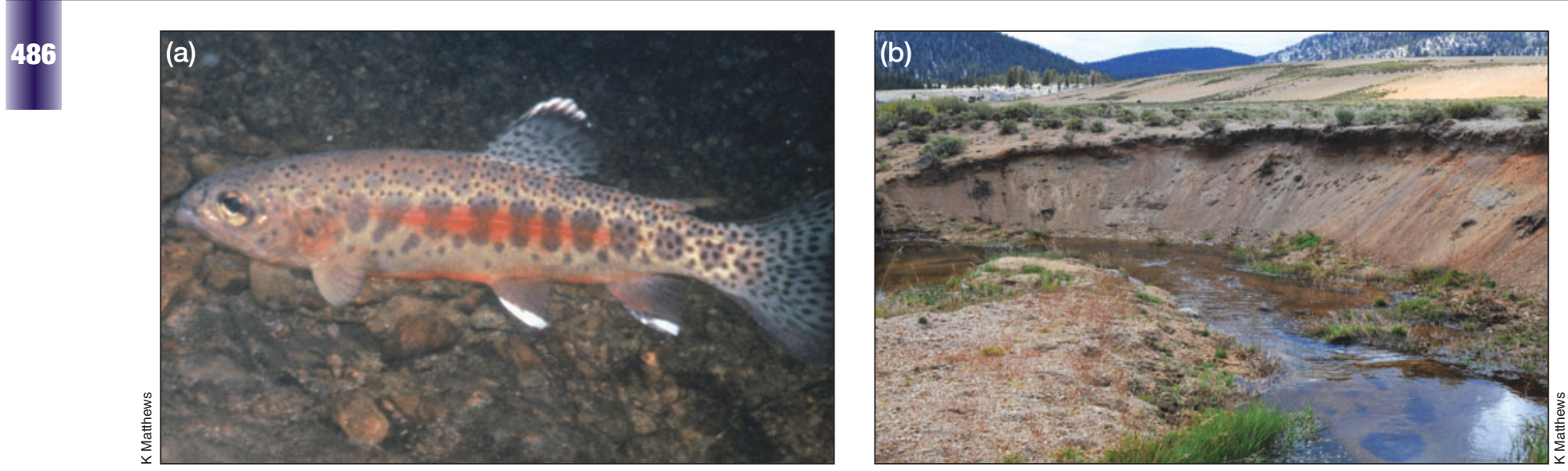

Figure 2. (a) California's state fish, the California golden trout (Oncorhynchus mykiss aguabonita). (b) Degraded trout habitat. (c) Restored trout habitat. Maintaining ecological integrity is the guiding objective in efforts to conserve this fish. The golden trout, indigenous to the cold streams of Golden Trout Creek and South Fork Kern River in the Golden Trout Wilderness of the high Sierra Nevada, California, faces compound threats to persistence throughout its native habitat (Knapp and Matthews 1996). "Light touch" activities to maintain stream integrity include reducing grazing impacts by fencing riparian corridors, planting vegetation along streams, stabilizing stream banks with rock armaments, and improving groundwater capacity by removing invasive shrubs in meadows.

systems that for nearly a century have been valued for the relative absence of intervention (Figure 1). To navigate this ongoing dilemma, we must articulate desired future conditions for park ecosystems in terms that carry greater clarity and specificity than do traditional notions of naturalness.

\section{Beyond naturalness}

The ambiguities inherent in a monolithic concept of naturalness and problems inherent in its use suggest the need to articulate alternative paths to the future. One path would reduce ambiguity by replacing the broader concept of naturalness with its more explicit (and sometimes conflicting) underlying meanings that are found in law, policy, and common usage - most notably historical fidelity and lack of intentional human intervention. Another path would also consider management goals that are more explicit, science-based, and measurable, notably ecological integrity and resilience.

\section{Ecological integrity}

In 1988, the Canada National Parks Act (www.gov.pe.ca/ law/statutes/pdf/n-01.pdf) replaced the notion of "natural" as a management endpoint with the concept of "ecological integrity", legally defined as "a condition that is determined to be characteristic of its natural region and likely to persist, including abiotic components and the

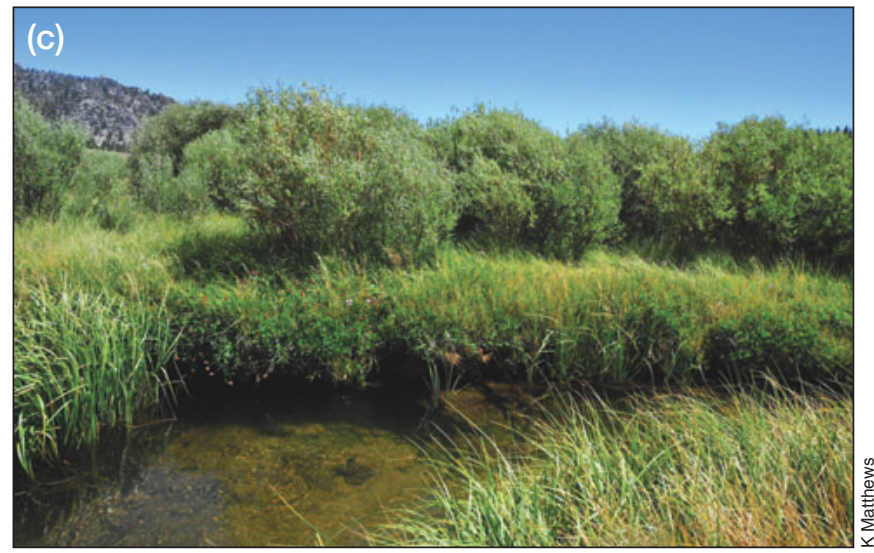

composition and abundance of native species and biological communities, rates of change, and supporting processes". At its heart, the Canadian definition of ecological integrity works from a deep theoretical understanding of ecosystems, based on optimizing thermodynamic efficiency, as expressed in food-chain lengths, nutrient cycling, and so on.

With ecological integrity as the goal, Parks Canada emphasizes retention of native ecosystem components. Biodiversity, ecosystem function, and stressors are carefully monitored. One of the key assumptions is that active management will often be required to maintain or restore ecological integrity and to keep park ecosystems within threshold conditions, especially for those parks that are heavily impacted by local anthropogenic change or where indigenous impacts shaped the historical structure and function of the park. Thresholds are set through consideration of reference ecosystems, standards and guidelines, historical reconstructions, biological patterns, trends, and expert opinion (Woodley 1993; Parks Canada Agency 2005).

The concept of ecological integrity shifts the focus from cause to effect and from past to future: desired attributes of future ecosystems can be defined without worrying about whether they were or were not caused or affected by humans. Under the guidance of ecological integrity, Canadian park managers do not attempt to eliminate every form of human disturbance; rather, they work to mimic some of the effects of aboriginal populations, 
where ecosystems coevolved with aboriginal management. Moreover, since specific landscapes can support many alternative ecosystem states while retaining ecological integrity, Parks Canada must determine which alternative states are preferred, in order to provide clear guidance and direction for interventions. Every 5 years, Parks

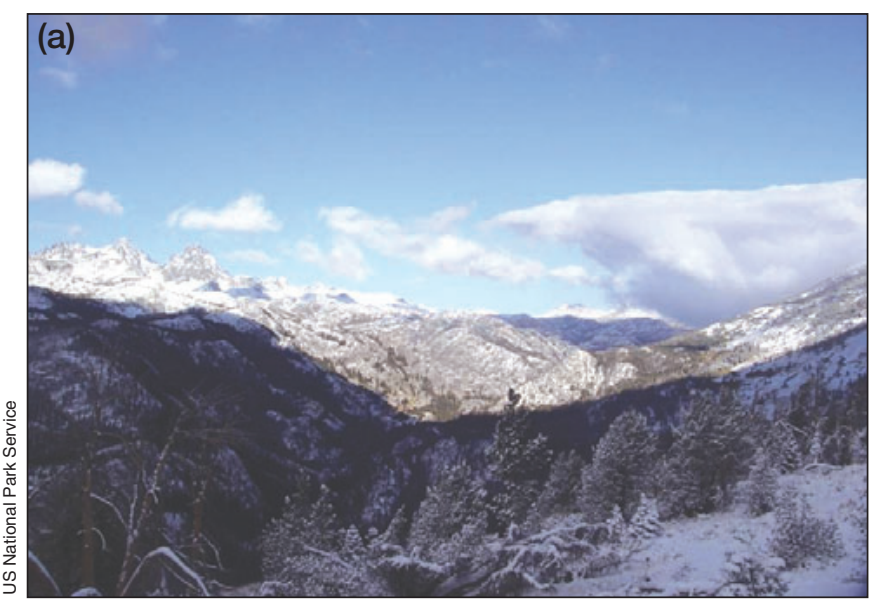

Canada requires the preparation of State of Park reports by each national park, complete with detailed indicators, measures, thresholds, and targets for management. These feed into Park Management Plans, which set an ecological vision and the required management actions for the park (Parks Canada Agency 2005).

Conserving biodiversity is a key feature of ecological integrity (Figure 2). Protected areas that adopt ecological integrity as a goal might maintain native biodiversity, even if community structure and composition fall outside the range of historical variability. Management interventions may be ongoing and large scale, to preserve particular ecosystem components (Figure 3).

\section{Resilience}

Resilience has also emerged as a useful concept, when dealing with dramatic but uncertain change. Resilience, as originally defined, is the capacity of a system to absorb change and persist without undergoing a state shift or fundamental loss of character (Holling 1973). Holling and

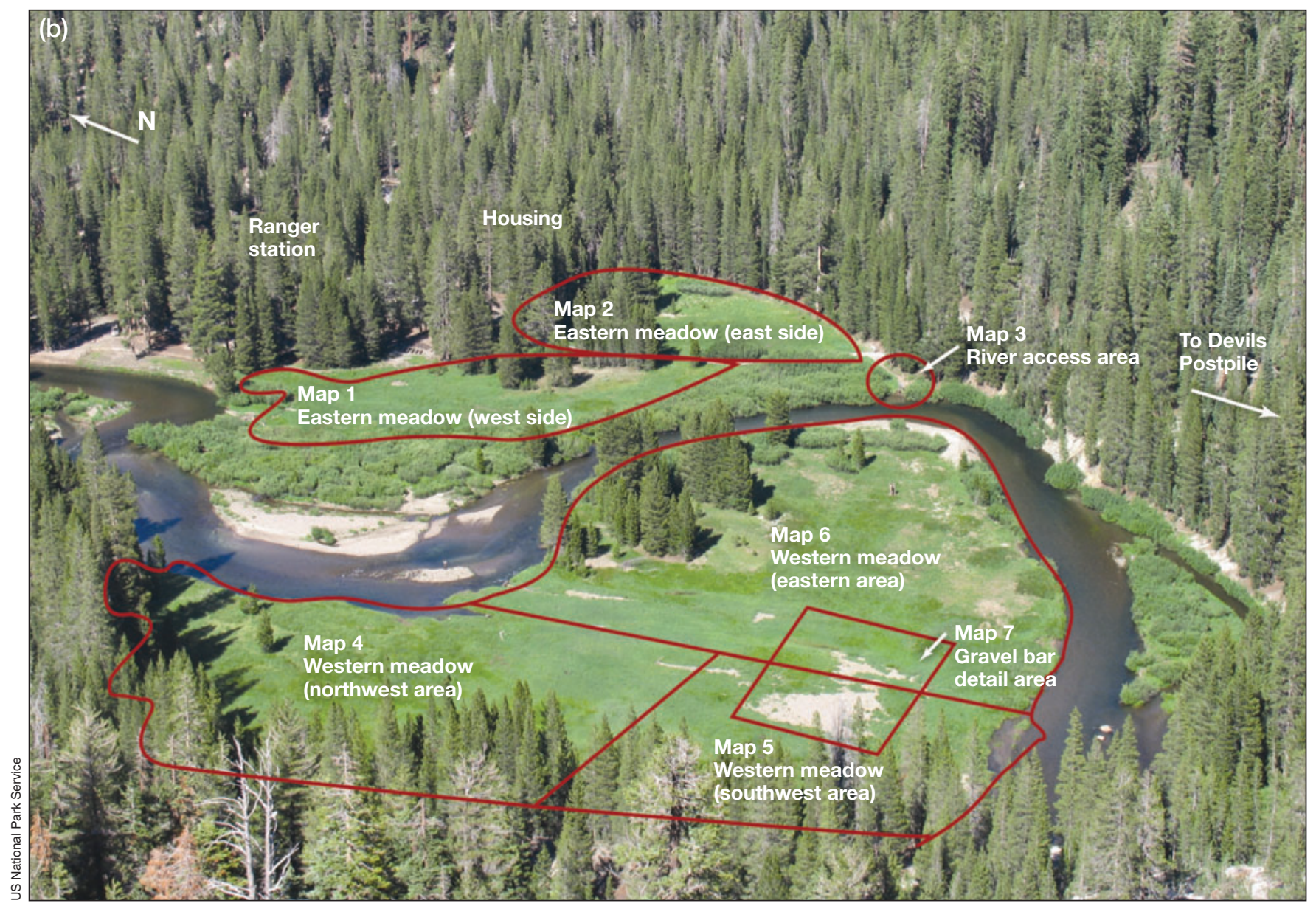

Figure 3. (a) Devils Postpile National Monument, in California, where managing the park as a refugium under climate change is being evaluated as a means to maintain ecological integrity. The location of this park, in a region of cold-air pooling (Daly et al. 2007), has been projected to protect its unusually rich biodiversity against warming temperatures by means of the buffering effects of its topography. (b) Zoned interventions, including conifer removal from meadows, aggressive control of invasives, reducing visitor impacts on meadows, minimizing groundwater pumping effects, planting native species within developed sites, and implementing a coordinated adaptive-management plan, are all being evaluated as part of an overall refugium framework. 

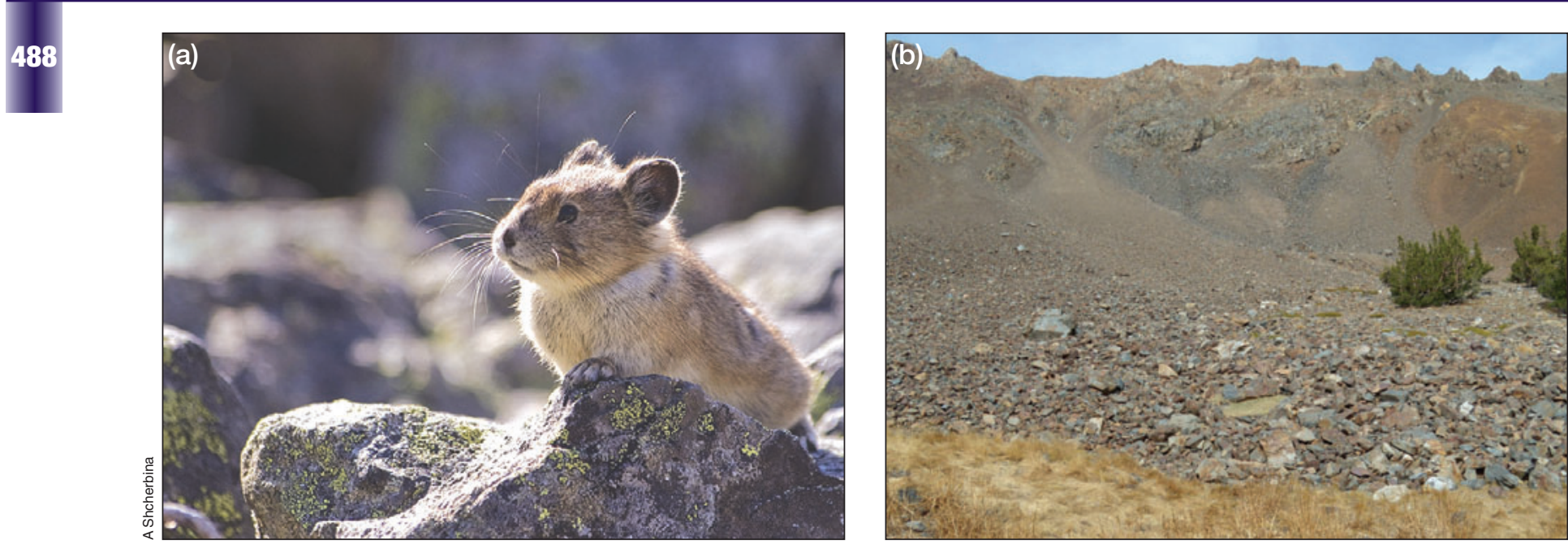

Figure 4. (a) Promoting resilience is essential in adaptation planning for the American pika (Ochotona princeps), a small, thermally sensitive, alpine mammal of western North American park and wilderness areas (Wolf et al. 2007). (b) Interventions to improve resilience to global warming in the pika's discontinuous talus (broken rock piles found on mountain slopes) habitat include delineating meadow and forage zones adjacent to pika taluses as conservation areas and excluding camping and packstock use in these areas; routing trails where they do not interrupt talus fields or fragment corridor environments between taluses, coupled with in-trail construction or renovations where slope support is required; using rock materials and designs that create pika habitat, especially corridor routes between talus fields; and using attractants, such as seedless hay, to lure pika along escape corridors to higher elevation talus fields.

others distinguish ecological (or social-ecological) resilience from engineering resilience (the rate at which a perturbed system returns to its initial state), which emphasizes efficiency rather than adaptive capacity. More importantly, resilience is a meaningful goal only if one specifies

Table 1. Broad strategies for promoting resilience and specific ways to promote each strategy (Chapin et al. 2006)

Reduce vulnerability by:

- Sustaining the slow variables (eg soil resources and the species pool) - the reserves in the system that accumulate slowly and provide buffers

- Mitigating the stresses that drive change

Enhance adaptability by:

- Fostering ecological, economic, and cultural diversity, including diversity in space and diversity in management strategies - protecting the building blocks for change that will maximize future options

- Creating capacity for learning and innovation at multiple scales

Enhance resilience by:

- Strengthening stabilizing feedbacks, particularly negative feedbacks and tight feedback loops, between actions and their consequences, but allowing sufficient disturbance so that systems can adjust to persistent changes in underlying controls

- Sustaining ecological and cultural legacies, including cultural connections to the land, thereby retaining system memory

- Building linkages across multiple scales, including adaptive governance and connectivity between parks and the surrounding landscape

Foster transformability (the ability to actively move to a desired novel system, as an alternative to passive degradation) by:

- Thinking outside the box

- Treating crisis as an opportunity for constructive change what is to be resilient, and to what it should be resilient.

The growing literature on resilience conceptualizes social and ecological systems as interlinked (Folke 2002; Gunderson and Holling 2002; Walker and Salt 2006), arguing for management across scales, with an understanding that park and wilderness areas must be managed in the context of larger landscapes and regional social, cultural, political, and ecological systems. According to resilience theory, attempting to prevent or resist change is likely to increase the risk of greater change in the future the past should not be preserved if it comes at the cost of reduced resilience. Several broad strategies for promoting resilience have been articulated (Table 1 ), along with specific ways to promote each strategy (Chapin et al. 2006).

Managing park and wilderness areas for ecological resilience might emphasize retaining ecosystem function over preserving specific species in situ. It might require letting go of the way landscapes look today, as conditions change, and identifying key processes to retain in the face of change, such that, although many other variables shift around, core functions and processes are preserved (Figure 4). Recommended tools for building resilience include experimentation, active adaptive management, and structured scenario planning - "envisioning alternative futures in ways that expose fundamental variables and branch points that can be collectively manipulated to evoke change" (Folke 2002).

\section{Adopting a pluralistic and adaptive landscape approach}

Biodiversity, historical fidelity, ecological integrity, resilience, and maintenance of nature's autonomy each has a unique meaning, and each has a legitimate place in 
the goals for park and wilderness areas. Each helps move beyond the inherent ambiguities of "naturalness", but each remains a general aspirational goal (similar to the ideas of justice or equality); much refinement is still needed, to create a set of policies and laws that govern the application of these concepts (and are subject to periodic revision and court opinion in terms of interpretation).

It is likely that the rich values of park and wilderness areas can be conserved only through a planned and deliberate diversity of management objectives. This would include preserving historical communities and landscapes, conserving specific endangered or endemic species, maintaining forest structure and function, allowing ecosystems to respond to change without human intervention (a hands-off approach), sustaining subsistence activities of indigenous peoples, and enhancing the resilience of a particular ecosystem. Managing to preserve historical landscapes will likely become more the exception than the rule, since in many cases such efforts will require ongoing intervention, investment of resources, and substantial management efforts. At the opposite end of the spectrum, managers may need to anticipate and guide change, to actively transform systems rather than allowing them to passively degrade - to create novel ecosystems in new places, for the purpose of protecting something of value and enhancing system resilience (Hobbs et al. 2006; Seastadt et al. 2008). The need for a diversity of approaches is even more critical, given the uncertainty about the impacts of climate change and other stressors.

This diversity of approaches could be undertaken within a single park, or different approaches could be applied across the entire protected-area system, by focusing different areas on different values (eg autonomous nature, historical fidelity, endangered species conservation). In either case, redundancy is important; similar strategies should be used in multiple locations (or different strategies in similar locations), to maximize opportunities to learn. Currently, goals and management strategies vary, but for the wrong reasons. This diversity is often the result of personal preference, available resources, lack of coordination, or even neglect. Instead, it should reflect a large-scale, planned, and deliberate effort that considers the appropriateness of interventions, scale, boundary effects, and how any particular area fits within a larger system of protected areas and the regional landscape. Some guidance for how this might be achieved is emerging in relation to landscape management in different parts of the world (eg Agnoleti 2006; Lindenmayer et al. 2008).

Although much has already been written about the need to carry out conservation planning at large scales (Margules and Pressey 2000; Liu and Taylor 2002; Hansen and DeFries 2007), there are few examples of successes in park and wilderness stewardship. Even without climate change, our existing park and wilderness areas are not large enough to sustain our natural heritage by themselves. Conservation planning must extend beyond the boundaries of park and wilderness areas, and climate change makes this scale of planning even more imperative. Political boundaries are fixed, but the biological landscape is not, particularly as biota respond to climate change (Lovejoy 2006). When combined with habitat fragmentation, species are less able to migrate to new sites as conditions change, making corridors and connectivity between protected areas and between protected areas and adjacent lands even more important than in the past.

Climate change and other novel stressors call for a very different type of planning model - one built around objectives that are frequently assessed and renegotiated. Goals may be enduring, but operational objectives probably need to be more flexible. What appear to be realistic future options may prove unrealistic, while new options may materialize. Managers will need to be more adaptive, regularly revisiting objectives and management decisions, and changing them as knowledge advances and uncertainty dissipates (Folke 2002). Managers need to be flexible enough for deliberate experimentation and effectiveness monitoring. At the same time, involvement of the public in participatory decision-making processes is essential to determine which goals and objectives are appropriate in which areas. Researchers also need to harness the potential provided by management activities and to conduct large-scale, meaningful experiments that have practical relevance to conservation and restoration in the face of rapid environmental change. The challenge, therefore, is to continue a dialogue among scientists, managers, and the public, and to focus on the very large questions surrounding park and wilderness-area management in a time of rapid environmental change.

\section{Acknowledgements}

We thank the Aldo Leopold Wilderness Research Institute for financial support to run two workshops during 2007-08, which led to the development of the ideas presented here. RJH received support from the Australian Research Council through an ARC Australian Professorial Fellowship.

\section{References}

Agnoleti M. 2006. The conservation of cultural landscapes. Wallingford, UK: CABI.

Alessa L and Chapin III FS. 2008. Anthropogenic biomes: a key contribution to Earth-system science. Trends Ecol Evol 23: 529-31.

Chapin III FS. 2007. Alaska parks in a warming climate: conserving a changing future. Alaska Park Sci 6: 7-11.

Chapin III FS, Lovecraft AL, Zavaleta ES, et al. 2006. Policy strategies to address sustainability of Alaskan boreal forests in response to directionally changing climate. P Natl Acad Sci USA 7: 16637-43.

Christensen NL. 1988. Succession and natural disturbance: paradigms, problems, and preservation of natural ecosystems. In: Agee JK and Johnson DR (Eds). Ecosystem management for parks and wilderness. Seattle, WA: University of Washington Press.

Cole DN. 2000. Paradox of the primeval: ecological restoration in wilderness. Ecol Restor 18: 77-86.

Cole DN and Landres PB. 1996. Threats to wilderness ecosystems: 
impacts and research needs. Ecol Appl 6: 168-84.

Daly C, Smith JW, and Smith JI. 2007. High-resolution spatial modelling of daily weather elements for a catchment in the Oregon Cascade Mountains, United States. J Appl Met Climat 46: $1565-86$.

Ellis EC and Ramankutty N. 2008. Putting people in the map: anthropogenic biomes of the world. Front Ecol Environ 6: 439-47.

Folke C (Ed). 2002. Navigating social-ecological systems: building resilience for complexity and change. Cambridge, UK: Cambridge University Press.

Gunderson LH and Holling CS (Eds). 2002. Panarchy: understanding transformations in human and natural systems. Washington, DC: Island Press.

Haines AM, Leu M, Svancara LK, et al. 2008. A theoretical approach to using human footprint data to assess landscape level conservation efforts. Conserv Lett 1: 165-72.

Hansen AJ and DeFries R. 2007. Ecological mechanisms linking protected areas to surrounding lands. Ecol Appl 17: 974-88.

Heyd T (Ed). 2005. Recognizing the autonomy of nature: theory and practice. New York, NY: Columbia University Press.

Higgs E. 2003. Nature by design: people, natural process, and ecological restoration. Cambridge, MA: MIT Press.

Hobbs RJ, Arico S, Aronson J, et al. 2006. Novel ecosystems: theoretical and management aspects of the new ecological world order. Global Ecol Biogeogr 15: 1-7.

Hobbs RJ and Cramer VA. 2008. Restoration ecology: interventionist approaches for restoring and maintaining ecosystem function in the face of rapid environmental change. Annu Rev Env Resour 33: 39-61.

Holling CS. 1973. Resilience and stability of ecological systems. Annu Rev Ecol Syst 4: 1-23.

Kay CE. 1995. Aboriginal overkill and native burning: implications for modern ecosystem management. West J Appl For 10: 121-26.

Knapp RA and Matthews KR. 1996. Livestock grazing, golden trout, and streams in the Golden Trout Wilderness, California: impacts and management implications. N Am J Fish Manag 16: 805-20.

Landres PB, White PW, Aplet G, and Zimmermann A. 1998. Naturalness and natural variability: definitions, concepts, and strategies for wilderness management. In: Kulhavy DL and Legg ML (Eds). Wilderness and natural areas in eastern North America: research, management, and planning. Nacogdoches, TX: Center for Applied Studies in Forestry, Stephen F Austin State University.

Lindenmayer D, Hobbs RJ, Montague-Drake R, et al. 2008. A checklist for ecological management of landscapes for conservation. Ecol Lett 11: 78-91.

Leopold AS, Cain SA, Cottam DM, et al. 1963. Wildlife management in the national parks. Trans North Am Wildl Nat Res Conf 28: $28-45$.

Liu J and Taylor W (Eds). 2002. Integrating landscape ecology into natural resource management. Cambridge, UK: Cambridge University Press.

Lovejoy TE. 2006. Protected areas: a prism for a changing world. Trends Ecol Evol 21: 329-33.

Mann CC. 2005. 1491: new revelations of the Americas before Columbus. New York, NY: Alfred A Knopf.

Margules CR and Pressey RL. 2000. Systematic conservation planning. Nature 405: 243-53.

NPS (National Park Service). 2006. Management policies 2006. www.nps.gov/policy/MP2006.pdf. Viewed 1 Oct 2009.
Parks Canada Agency. 2005. Monitoring and reporting ecological integrity in Canada's National Parks. Volume I: guiding principles. Ottawa, Canada: Ontario Parks Canada Agency.

Peterken GF. 1996. Natural woodland: ecology and conservation in northern temperate regions. Cambridge, UK: Cambridge University Press.

Pyne SJ. 1997. Fire in America: a cultural history of wildland and rural fire. Seattle, WA: University of Washington Press.

Ralston HI. 2001. Natural and unnatural; wild and cultural. West N Am Naturalist 6: 267-76.

Ridder B. 2007. The naturalness versus wildness debate: ambiguity, inconsistency, and unattainable objectivity. Restor Ecol 15: $8-12$.

Sanderson EW, Jaiteh M, Levy MA, et al. 2002. The human footprint and the last of the wild. BioScience 52: 891-904.

Seastadt TR, Hobbs RJ, and Suding KN. 2008. Management of novel ecosystems: are novel approaches required? Front Ecol Environ 6: 547-53.

Sellars RW. 1997. Preserving nature in the National Parks: a history. New Haven, CT: Yale University Press.

Society for Ecological Restoration International Science and Policy Working Group. 2004. The SER International primer on ecological restoration. Tuscon, AZ: Society for Ecological Restoration International.

Vale TR. 2002. The pre-European landscape of the United States: pristine or humanized? In: Vale TR (Ed). Fire, native peoples, and the natural landscape. Washington, DC: Island Press.

Walker B and Salt D. 2006. Resilience thinking: sustaining ecosystems and people in a changing world. Washington, DC: Island Press.

White PS and Bratton SP. 1980. After preservation: philosophical and practical problems of change. Biol Conserv 18: 241-55.

Wolf S, Nowicki B, and Siegel K. 2007. Petition to list the American pika (Ochotona princeps) as threatened or endangered under the United States Endangered Species Act. Petition before the Secretary of Interior, US Fish and Wildlife Service. Tuscon, AZ: Center for Biological Diversity.

Woodley S. 1993. Monitoring for ecological integrity in Canadian National Parks. In: Woodley SJ, Francis G, and Kay J (Eds). Ecosystem integrity and management of ecosystems. Delray Beach, FL: St Lucie Press.

Wu J and Loucks OL. 1995. From balance of nature to hierarchical patch dynamics: a paradigm shift in ecology. Quart Rev Biol 70: 439-66.

${ }^{4}$ Environmental Studies Department, University of California, Santa Cruz, CA; ${ }^{5}$ The Wilderness Society, Denver, CO; ${ }^{6}$ Department of Biology and Wildlife, University of Alaska, Fairbanks, AK; ${ }^{7}$ US Geological Survey Western Ecological Research Center, Three Rivers, CA; ${ }^{8}$ Department of Biology, University of North Carolina, Chapel Hill, NC; ${ }^{9}$ Sequoia and Kings Canyon National Parks, Three Rivers, CA; ${ }^{10}$ School of Environmental Studies, University of Victoria, Victoria, British Columbia, Canada; ${ }^{11}$ Pacific Southwest Research Station, USDA Forest Service, Berkeley, CA; ${ }^{12}$ The Nature Conservancy and Department of Vegetable Crops and Weed Science, University of California, Davis, CA; ${ }^{13}$ Rocky Mountains Cooperative Ecosystem Studies Unit, College of Forestry and Conservation, University of Montana, Missoula, MT; ${ }^{14}$ Ecosystem Science, Parks Canada, Gatineau, Quebec, Canada 